\title{
Ultrasound in the food and processing industry
}

\author{
N. L. Morgunova*, F. Ya. Rudik, and N. A. Semilet \\ Saratov State Vavilov Agrarian University, 410012, 1, Teatralnaya sq., Saratov, Russian Federation
}

\begin{abstract}
Many processes take place in the food and processing industry for a long period of time. The authors of the article, based on experimental studies, propose to intensify the processes of humidification, washing, disinfection and extraction using low-frequency ultrasound. Laboratory ultrasound installations with an ultrasound frequency of $18-35 \mathrm{kHz}$ were used for research.
\end{abstract}

\section{Introduction}

When preparing grain for simple grinding, the technical means used do not make it possible to obtain high-quality cleaning of hard-to-reach areas of the shell from traces of contamination and mineral contamination. The humidification process is very long (from 8 to 48 hours) [1]. This affects the quality of wallpaper flour. The use of thermal and chemical methods of inactivation of trypsin and urease inhibitors negatively affects the amino acids of the protein macromolecule, sharply reducing their nutritional value [2].

The basis of the hydrodynamic effect of liquid on materials is the ability of liquid to penetrate into all voids and capillaries of the material, to change their structural, mechanical and biological properties. A feature of the processes occurring under the influence of lowfrequency ultrasound is the intensification of hydromechanical and mass transfer processes. The frequency, intensity of ultrasound, processing time, temperature changes and the addition of additional substances during the processing of various cereals, oilseeds and legumes are the determining parameters of the intensification of processes [3]. Thus, when processing grain, the effect of low-frequency ultrasound makes it possible to perfectly clean the surface of the grain, even in hard-to-reach places, for example, in the area of the beard and furrow of wheat grain, as well as speed up the humidification process and ensure microbiological safety [4]. When processing legumes, it is possible to achieve both acceleration of grain swelling and inactivation of anti-nutritional substances [5]. The use of low-frequency ultrasound in the food industry is a promising scientific direction [6-8].

\section{Methods}

During the experimental studies, soy grains "Zlata", "Bara", "Soer-4", "Soer-5" were used. Urease activity was determined according to GOST 13979.9-69, trypsin inhibitor activity was determined by the caseinolytic method of M. L. Kakeid (modified by I. I. Benken). Wheat grain of the "Saratovskaya 29" variety was examined. Grain quality indicators were

\footnotetext{
*Corresponding author: morgunovanl@mail.ru
} 
determined by standard methods (GOST 10847-74, GOST 13586.5-93). Experimental planning and processing of experimental studies were carried out in the program Statistica.10 and Excel. Experimental studies were conducted on the basis of the Saratov State Vavilov Agrarian University and LLC "Ultrazvuk TeO" with the help of UOM - 2, PSB - Gals, RAP-01, UZU-4 installations with an ultrasonic vibration frequency of 18-35 $\mathrm{kHz}$ and an ultrasound intensity of $0.3-2 \mathrm{~W} / \mathrm{cm}^{2}$.

\section{Results and discussion}

The paper investigated the issues of theoretical and applied interaction of hydrodynamic and acoustic diffusion vibrational forces of mass transfer in order to identify the possibility of increasing the technological impact on the parameters of moistening and cleaning the grain shell before grinding and extraction of anti-nutrients in soybean grain. An important component of the grain shell cleaning process is the processing time at a set frequency of ultrasonic vibrations. From these positions, the dependence of the water heating temperature on the voicing time at a constant oscillation frequency of $18 \mathrm{kHz}$ was studied. It has been found that even with a slight increase in water temperature to $30{ }^{\circ} \mathrm{C}$, the process of cavitation exposure to pollutants increases sharply and this indicates an increase in cavitation vapor-air bubbles. The regularity of reducing the contamination and contamination of grain at variable ultrasound frequencies and processing time was also revealed - Figures 1 (A-D).

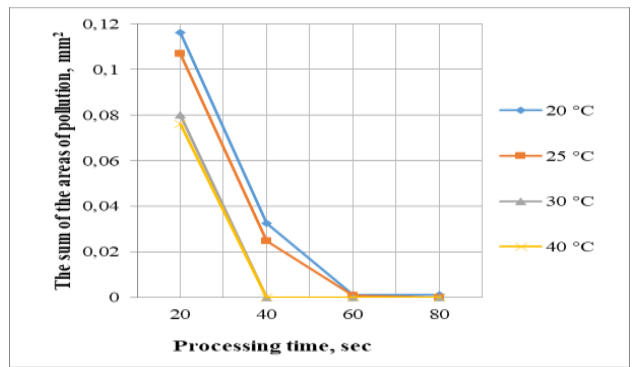

A. Graph of the dependence of the change in the total area of contamination of the grain surface on the processing time and water temperature with a frequency of ultrasonic vibrations of $18 \mathrm{kHz}$.

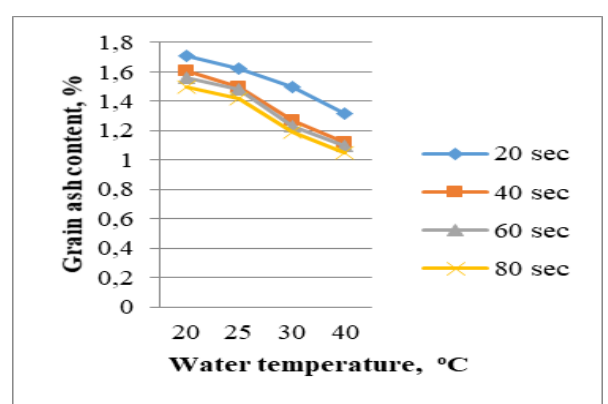

C.Graph of the dependence of the change in grain ash content on the processing time and water temperature with a frequency of ultrasonic vibrations of $18 \mathrm{kHz}$.

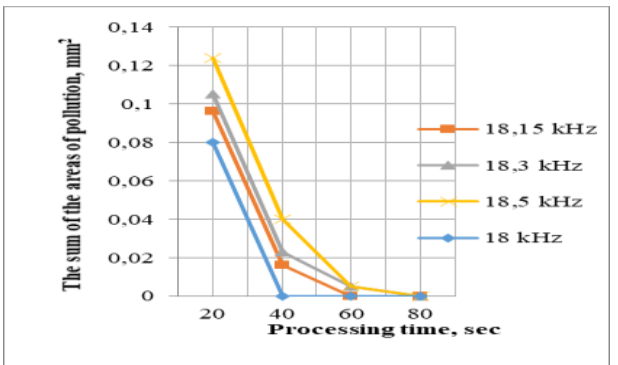

B. Graph of the dependence of the change in the total area of contamination of the grain surface on the variables of its processing time and frequency of ultrasonic vibrations at its processing temperature of $30^{\circ} \mathrm{C}$.

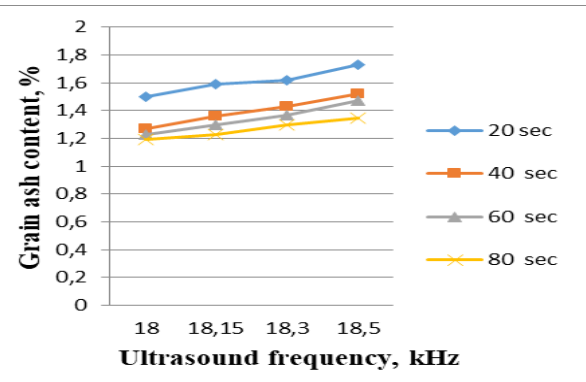

D. Graph of the dependence of the change in grain ash content on the variables of its processing time and frequency of ultrasonic vibrations at its processing temperature of $30^{\circ} \mathrm{C}$.

Fig.1.The regularity of reducing contamination and clogging of grain at variable ultrasound frequencies and processing time was also revealed. 
When water is heated to $30{ }^{\circ} \mathrm{C}$ and cleaned for 40 seconds, Figure 1, there is a sharp decrease in grain contamination.On average, wheat and rye grains have an ash content of $1.5 \ldots 2.3 \%$, and grain shells $-3.5 \ldots 24.5 \%$. At the same time, most of the mineral substances, up to $65 \%$, are on the grain shell. Thus, with the complete removal of mineral contaminants, traces of mold fungi and pests, the ash content in the grain can be brought to sufficiently high levels. Experimental studies of grain moisture have shown that the required normalized grain moisture values (14.5-17\%) are achieved when treated with ultrasound with a frequency of $18.0-18.15 \mathrm{kHz}$, a temperature of $30^{\circ} \mathrm{C}$ and a processing time of 20-30 seconds.

In the presence of a huge number of useful components in soy - protein up to $60 \%$, fat up to $22 \%$, fiber up to $7 \%$ and, especially, all nine essential amino acids, soy also has two sharply negative components - inhibitors of trypsin and urease enzymes [9]. Their activity reduces the nutritional value of feed and food. In order to reduce them, high-temperature treatment is used, which leads to the denaturation of protein as a whole, amino acids and vitamins, which leads to significant losses of the protein value of the product. It is established that the main evaluation factors determining the efficiency of processing are: the degree of grinding of seeds, the concentration of oxidizer in the working solution, the frequency of ultrasound and the processing time. The dynamics of extraction after processing soybean grain by ultrasound is shown in Figure 2.

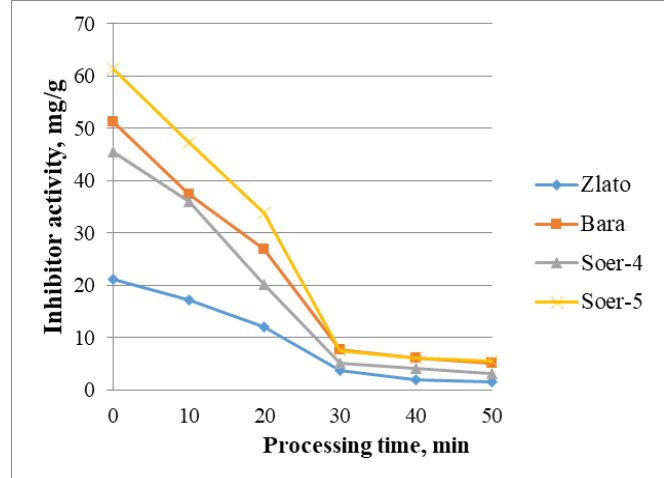

A. Graph of the dependence of the activity of the trypsin inhibitor on the treatment time with an ultrasound frequency of $18 \mathrm{kHz}$.

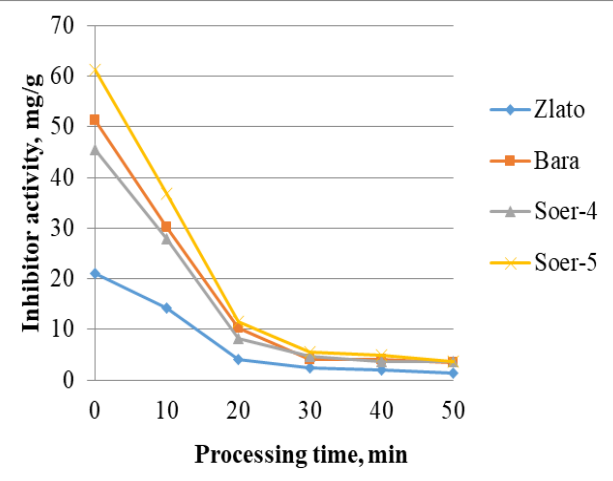

B. Graph of the dependence of the activity of the trypsin inhibitor on the treatment time with an ultrasound frequency of $20 \mathrm{kHz}$.

Fig.2.The dynamics of extraction after processing soybean grain by ultrasound is shown.

The results of the research have established that during the first 10-15 minutes of grain processing by ultrasound, the initial inactivation process proceeds, and subsequently the process proceeds more intensively. The activity of the inhibitor already decreases to 2-7 $\mathrm{mg} / \mathrm{g}$ after 30 minutes of ultrasound treatment. This circumstance fully confirms the analytical prerequisites for high technological processing of soybean grain by ultrasound [10].

\section{Conclusion}

Thus, the use of ultrasonic processing will significantly speed up the processes of grain preparation for grinding, and inactivation of anti-nutrients in soy in the production of animal feed and food. 


\section{References}

1. A. I. Altukhov, Journal "Bulletin of the Kursk State Agricultural Academy", 5 (2005)

2. F. Ya. Rudik, B. P. Zagorodskikh, N. L. Morgunova, Yu. A. Kodatsky, Mordovia University Bulletin, 28, 2 (2018)

3. F. Y. Rudik, N. L. Morgunova, N. A. Semilet, L.G. Lovtsova, Z. I. Ivanova, IOP Conf. Series: Materials Science and Engineering, 862 (2020)

4. F. Y. Rudik, N. L. Morgunova, E. S. Krasnikova, E. A. Faust, N. A. Semilet, Storage and processing of agricultural raw materials, 1 (2020)

5. F. Y. Rudik, N. L. Morgunova, N. A. Semilet, I. R. U. Abdumalikov, D.V. Makarov, Agrarian Scientific Journal, 3 (2020)

6. T. S. Awada, H. A. Moharram, O. E. Shaltout, D. Asker, M. M. Youssef, Food Research Int., 48 (2012)

7. H. Feng, G. Barbosa-Canovas, J. Weiss, Ultrasound Technologies for Food and Bioprocessing (Food Engineering Series) (2011)

8. Z. Chen, J. Food Microbiol Saf Hyg., 102, 2 (2017)

9. S. V. Kalashnikova, T. N. Tertychnaya, XII National Scientific and Practical Conference with international participation «Technologies and healthy food products» (Saratov, 2021)

10. V. N. Khmelev, Application of high-intensity ultrasound in industry (Biysk, Publishing House of Alt.state Technical University) (2010) 